\title{
From Smoking to Cancers: Novel Targets to Neuronal Nicotinic Acetylcholine Receptors
}

\author{
Chia-Hwa Lee, ${ }^{1}$ Chih-Hsiung Wu, ${ }^{2}$ and Yuan-Soon $\mathrm{Ho}^{1,3,4}$ \\ ${ }^{1}$ Graduate Institute of Medical Sciences, Taipei Medical University, Taipei 110, Taiwan \\ ${ }^{2}$ Department of Surgery, School of Medicine, Taipei Medical University, Shuang Ho Hospital, Taipei 235, Taiwan \\ ${ }^{3}$ Department of Laboratory Medicine, Taipei Medical University Hospital, Taipei 110, Taiwan \\ ${ }^{4}$ Center of Excellence for Cancer Research, Taipei Medical University, Taipei 110, Taiwan \\ Correspondence should be addressed to Yuan-Soon Ho, hoyuansn@tmu.edu.tw
}

Received 14 December 2010; Revised 18 February 2011; Accepted 17 March 2011

Academic Editor: Sushant Kachhap

Copyright () 2011 Chia-Hwa Lee et al. This is an open access article distributed under the Creative Commons Attribution License, which permits unrestricted use, distribution, and reproduction in any medium, provided the original work is properly cited.

Cigarette smoking bears a strong etiological association with many neovascularization-related diseases, including cancer, cardiovascular disease, and age-related macular degeneration. Cigarette smoke is a complex mixture of many compounds, including nicotine, which is the major active and addictive component of tobacco. Nicotine and its specific metabolized carcinogens directly bind to nicotinic acetylcholine receptors (nAChRs) on cell membranes and trigger the nAChR signal cascade. The nAChRs were originally thought to be ligand-gated ion channels that modulate physiological processes ranging from neurotransmission to cancer signaling. For several decades, the nAChRs served as a prototypic molecule for neurotransmitter receptors; however, they are now important therapeutic targets for various diseases, including Alzheimer's and Parkinson's diseases, schizophrenia, and even cancer. This paper describes recent advances in our understanding of the assembly, activity, and biological functions of nicotinic receptors, as well as developments in the therapeutic application of nicotinic receptor ligands.

\section{Introduction}

The impact of tobacco use on mortality and morbidity is well known. As far back as 1982, the Surgeon General of the United States Public Health Service has concluded that cigarette smoking is the major single cause of cancer mortality in the United States. Recently, the World Health Organization (WHO) reported in 2010 that almost one billion people and 250 million women are daily smokers. The tobacco epidemic kills 5.4 million people in average per year from lung cancer, heart disease, and other illnesses, and approximately 650,000 of these deaths are caused by second-hand smoke. If this smoking trend continues, there will be more than 8 million deaths every year, with more than $80 \%$ of tobacco-related deaths in developing countries by 2030 . Consequently, tobacco will kill a billion people due to smoking-related disease during this century, with tobacco use-related cancers being one of the main causes of death.

Tobacco use is by far the most widespread factor causing exposure to known carcinogens and death from cancer and is therefore a model for understanding mechanisms of cancer induction. A causal relationship was reported between active smoking and cardiovascular diseases, respiratory diseases, reproductive disorders, and several types of cancers, including cancers of the lung, bladder, cervix, esophagus, kidney, larynx, mouth, pancreas, stomach, and leukemia [1]. Although it might seem obvious that carcinogens associated with the use of tobacco products have caused numerous cancers, the effects of cancer genes, protein complexes, cellular circuitry, and signal transduction pathways are often overlooked.

According to the report from the International Agency for Research on Cancer in 2010, cigarette smoke contains a diverse array of 4,000 chemicals, 250 of which are known to be harmful, and more than 60 known carcinogens have been detected in mainstream cigarette smoke, and most of the same carcinogens are also present in second-hand smoke. The most potent of these carcinogens are polycyclic aromatic hydrocarbons and nicotine-specific metabolites, such as 4-(methylnitrosamino)-1-(3-pyridyl)-1-butanone (NNK) 
and N-nitrosonornicotine (NNN). These nitrosamines form DNA adducts cause mutations that lead to cancer [2]. DNA adducts have been proposed as potential markers of exposure to tobacco carcinogens, and these markers may help provide an integrated measure of carcinogen exposure relevant to individual cancer risk assessment. The adduct levels are generally higher in lung tissues of smokers than those of nonsmokers while studies using blood DNA have produced mixed results. In the following sections, we review evidence showing how nicotine or nicotine-specific metabolic nitrosamines, NNK or NNN, promote cancer development through the physical interaction with nicotinic acetylcholine receptors ( $\mathrm{nAChRs).}$

\section{Genomewide Association of nAChRs with Lung Cancer}

Many studies have pointed out that the binding of exogenous nicotine, NNK, NNN, and acetylcholine to nAChRs, respectively, will stimulate the growth of both small cell lung carcinomas (SCLCs) and nonsmall cell lung carcinomas (NSCLCs) [3]. Two similar studies also showed that the autocrine interaction of acetylcholine (Ach) and estrogen with the nAChR will stimulate SCLC and breast cancer cell proliferation [4-6]. To identify genetic factors involved in smoking-mediated cancer risk, a genomewide association study of 317, 139 single-nucleotide polymorphisms was recently performed using DNA from 1,989 lung cancer patients and 2,625 control subjects from six central European countries [7]. A locus in the 15q25 chromosome region was found to be strongly associated with lung cancer [8]. Interestingly, this region contains several genes, including three nAChR subunits (CHRNA5, CHRNA3, and CHRNB4, encoding the $\alpha 5, \alpha 3$, and $\beta 4$ subunits, resp.) that are predominantly expressed in neurons and other tissues (particularly alveolar epithelial cells, pulmonary neuroendocrine cells, and lung cancer cell lines) $[7,9,10]$. Previous studies have also suggested that $N^{\prime}$-nitrosonornicotine and nitrosamines may facilitate neoplastic transformation by stimulating angiogenesis and tumor growth mediated through their interaction with nicotinic acetylcholine receptors $[11,12]$. The activation of these receptors can also be inhibited by nicotine receptor antagonists, which confirms that nAChRs play important roles in disease development and implies possible chemoprevention opportunities for lung cancer [13]. Therefore, further analyses of multiple diverse populations will be required to confirm this locus and to identify additional lung cancer susceptibility.

\section{Nicotinic Acetylcholine Receptor Structure}

The nicotinic acetylcholine receptors (nAChRs) belong to the superfamily of the Cys-loop ligand-gated ion channels (LGICs), which also include the GABA, glycine, and 5-HT3 receptors. They are formed by the assembly of five transmembrane subunits selected from a pool of 17 homologous polypeptides $(\alpha 1-10, \beta 1-4, \gamma, \delta$, and $\varepsilon)$. There are many nAChR subtypes, each consisting of a specific combination of subunits, which mediate diverse physiological functions.
These receptors are widely expressed in the central nervous system, and, in the periphery, they mediate synaptic transmission at neuromuscular junctions and ganglia. Recently, the cDNAs for all types of nAChR subunits have been cloned from neuronal and nonneuronal cells, such as keratinocytes, epithelia, and macrophages, which encompass the main domains of the ligand-binding sites.

Based on the different ligand-binding properties of these $\mathrm{nAChRs}$, the nAChRs are divided into two main classes: (1) the $\alpha$-bungarotoxin-( $\alpha$-Bgtx-) binding nAChRs, which are mainly homopentamers of $\alpha 7, \alpha 8$, or $\alpha 9$ subunits; (2) nAChRs, which do not bind $\alpha$-Bgtx but consist of the $\alpha 2-\alpha 6$ and $\beta 2-\beta 4$ subunits, exist only as heteropentamers and bind agonists with high affinity [14]. The presence of a certain subunit can affect the localization, biophysical, functional, and pharmacological properties of the nAChRs, as well as the regulation of the expression of the $\mathrm{nACh}$ subtype at the developmental or adult stage in some specific cells. The absence of a subunit may lead to the compensatory upregulation of other subtypes [15].

Because nAChR subunits exhibit a high degree of evolutionary conservation, studies of high-resolution Xray crystallographic and electron microscopic analyses of proteins related to $\mathrm{nAChRs}$ have provided considerable insight into how structure imparts functional similarities and differences among all nAChRs.

Multiple nAChR subunit compositions are expressed in the central and peripheral nervous system, but the most represented receptors are $\alpha 4 \beta 2$ and $\alpha 7$ in the brain and $\alpha 3 \beta 4$ in the peripheral nervous system. In these nAChRs, $\alpha 4 \beta 2$-composed nAChRs have the highest affinity to nicotine $[16,17]$. In addition, only the $\alpha 4$ and $\beta 2$ subunits are found on GABA-Aergic neurons [18]. Another study pointed out that $\alpha 4 \beta 2$ levels can be upregulated by proinflammation cytokines, such as TNF- $\alpha$ [19] through p38-MAPK signaling pathways. This important discovery reveals the complexity of the interaction network between nAChRs and the inflammation factors. By contrast, compared to $\alpha 4 \beta 2$ nAChR, $\alpha 7$ homopentameric nAChR is the most well-known and investigated type of nAChR. Receptors composed of $\alpha 7$ subunits are known to desensitize rapidly and to have a high $\mathrm{Ca}^{+}: \mathrm{Na}^{+}$permeability ratio that exceeds that of the glutamate NMDA receptor [20-22] and the 3-4:1 ratio of most other nAChRs. The signaling pathway encourages scientists to look further into carcinogenetic mechanisms underlying $\alpha 7$-nAChRs-related lung [23], bladder [24], and colon cancers [25], as well as $\alpha 9$-nAChRs in breast cancers [26-28]. In fact, some receptors (such as $\alpha 7, \alpha 9$, and $\alpha 10$ ) have highly specialized functions including those pertaining to the regulation of signaling mechanisms used by sensory epithelia and other nonneuronal cell types [29].

\section{4. nAChR Signaling Pathways}

Cigarette smoking has a strong etiological association with the development and progression of several types of cancers, cardiovascular disease, diabetic retinopathy, and age-related macular degeneration. Nicotine is the major active and addictive component of cigarette smoke. Previous studies 
demonstrated that the average plasma nicotine concentration of active smokers is about $100 \mathrm{nM}$ to $1 \mu \mathrm{M}$ [30, 31]. In addition to active cigarette smoking, exposure to second-hand smoke is another mode of nicotine exposure [32]. When the biological levels of nicotine associated with second-hand smoke exposure were measured, a positive correlation between second-hand smoke exposure and concentrations of nicotine in the body was found. To date, it is well known that the specific nicotine-metabolized, tobaccospecific carcinogenic nitrosamines NNK and NNN are strong mutagens associated with several cancers, including lung, bladder, colon, and breast cancers [33-38]. Through binding of several ligands and nAChRs, signaling transductions are able to activate and promote cell proliferation, migration, and metastasis in cancer cells.

As the nAChRs are ligand-gated cationic channels, their different subtypes, such as neuronal nAChRs, are differentially permeable to calcium ions $[39,40]$. The calcium permeability of homomeric receptors is significantly higher than heteromeric nAChRs $[39,40]$. In particular, the $\alpha 7$ containing nAChRs are generally considered to be the most permeable receptors to calcium, and their activation can raise cytoplasmic calcium levels and trigger a series of calcium-dependent intracellular processes $[39,40]$. Recent studies have demonstrated the presence of nAChRs in several nonneuronal, nonexcitable cells, including bronchial epithelium, endothelial cells, keratinocytes, immune cells, and vascular smooth muscle cells [15, 41, 42]. The presence of these receptors in nonneuronal cells seems to suggest that they have distinct functions well beyond neurotransmission [43-49].

Several convergent studies have indicated that the $\alpha 7$-nAChRs primarily mediate endothelial cell proliferation, invasion, and angiogenesis [50-55]. The presence of $\alpha 7$-nAChR inhibitors like methyllycaconitine (MLA) and $\alpha$-bungarotoxin could reverse the proangiogenic effects of nicotine. However, it must be noted that both $\alpha$ bungarotoxin and MLA also bind with high affinity to $\alpha 9$ nAChR. Therefore, there may be partial involvement of $\alpha 9-\mathrm{nAChR}$ in the proangiogenic effects of nicotine [56]. The involvement of nAChR subunits in nicotine-induced angiogenesis was further verified by siRNA techniques.

In general, nicotine induced cell proliferation, angiogenesis, migration, and apoptosis through nAChR-associated downstream signal transduction such as MAP Kinase, PI3kinase/Akt, NF- $\kappa \mathrm{B}$, and $\beta$-arrestin pathways [50-53, 57-60]. Through the above signal transduction, it is found that in nonneuronal tissues, nicotine induces the secretion of growth factors such as $\beta$ FGF, TGF $\alpha$, VEGF, PDGF [61], and the upregulation of the calpain family of proteins [62], COX-2 and VEGFR-2 [63]. Most intriguingly, both VEGF- and $\beta$ FGF-induced human microvascular endothelial cell (HMVEC) migration and angiogenesis require $\mathrm{nAChR}$ activation [64].

Mechanistically, nicotine has been shown to induce activation of NF- $\kappa$ B through the MAP kinase and PI3K/AKT signaling pathways, which promote survival, proliferation, and angiogenesis of endothelial cells [65]. Further study showed pharmacological dissection of nicotine's influence on cell cycle progression, apoptosis, and differentiation [43], and this indicates that $\alpha 7$-nAChRs expressed in keratinocytes are important. In addition, large-cell carcinoma, squamouscell carcinoma, adenocarcinoma of small airway, and alveolar type II cell of origin, as well as immortalized large- and small-airway epithelial cells all confirmed that nicotine and NNK activate the PI3K-Akt pathway and NF- $\kappa$ B, resulting in stimulation of proliferation and inhibition of chemotherapyinduced apoptosis $[66,67]$. Recently, a study also demonstrated that AKT survival signals play an important role in the nicotine-mediated carcinogenic process in human breast cancer cells [28].

In addition, $\beta$-arrestin- 1 and Src kinase also appear to be the key players in mediating the mitogenic effects of nicotine. The Src family of protein tyrosine kinases has been found to be a critical component of multiple receptormediated signaling pathways that regulate proliferation, survival, metastasis, and angiogenesis. Additionally, nicotine also promotes cancer cell invasion by inducing matrix metalloproteinases 2 and 9, as well as the expression of plasminogen activators (urokinase-type plasminogen activator and its receptor) through COX-2 and VEGFR regulation [63].

Taken together, nicotine promotes cell proliferation and tumor angiogenesis via the stimulation of nAChRs. Nicotinic receptor antagonists, such as mecamylamine and $\alpha$ bungarotoxin, demonstrate potent therapeutic application. Therefore, the development of specific, potent nAChR analogs and antagonists could provide novel approaches for the treatment of neovascularization-related diseases including cancer, cardiovascular disease, and macular degeneration.

\section{Smoking, nAChRs, and Cancer}

Cigarette smoking bears a strong etiological association with cancers. To the best of our knowledge, smokinginduced transformation can be abstracted into two aspects: (1) among the mixture of cigarette smoking compounds, NNK and NNN play the role of initiators in carcinogenesis (indirect-acting carcinogens, the most important tumorigenesis model in lung and bladder cancers). In contrast, nicotine has been demonstrated as a cocarcinogenic factor by playing a promoter role of carcinogenesis in tobacco replacement therapies [68]. Nicotine and NNK are considered to be carcinogens that react to DNA, and most reports have proposed that the chemical properties of the resulting DNA adducts can cause diverse genetic changes known to exist in human cancers [69-71]. (2) Nicotine, NNN or NNK have strong abilities to upregulate $\mathrm{nAChR}$ expressions which promote signals cascade, all these events result in a strong feedback loop and cause enhancement of cancer cell proliferation, migration, and metastasis. Therefore, understanding the functional diversity of the nAChR in each tissue could offer useful and abundant prospects for the designing of the novel cancer therapeutics stratagem.

Since the brain is the best organ to characterize the role of $\mathrm{nAChR}$ in the regulation of the neurotransmitter acetylcholine [72], the interaction of nicotine with $\mathrm{nAChR}$ 
subunits in the brain provides the basis for nicotine addiction. For decades, nAChRs were generally believed to exist only in the nervous system (neuronal nAChRs) and at neuromuscular junctions (muscle nAChRs). However, in the past 20 years, increasing studies have shown that nAChRs can also be expressed in oral [34], mechanosensory hair [73], and airway epithelium cells $[74,75]$, where they play different roles in normal cell development and function. Furthermore, recent studies have also shown evidence that nAChRs and their physiological ligands such as choline and acetylcholine are universally expressed in mammalian and, more importantly, in cancer cells [24-26, 76-80]. The first study that implicated $\mathrm{nAChRs}$ in cancer growth regulation was reported in 1989 [81], and in the following decades, many studies indicated that nAChRs are the key molecular and central regulators of a complex network of stimulatory and inhibitory neurotransmitters that govern the synthesis and release of growth [23, 26, 82, 83], angiogenic [58], metastasis [25], and even apoptosis [84-86] in cancer cells microenvironment. In addition, the nAChRs are also found to trigger intracellular signaling pathways in a cell-typespecific manner.

The expression of $\mathrm{nAChRs}$ in mammalian cells and their diverse regulatory functions suggest that the modulation of these receptors, owing to chronic exposure to tobacco constituents or other environmental and lifestyle factors, contribute to the development of cancer [1]. This hypothesis was supported by the discovery that the tobacco-specific carcinogenic nitrosamines NNK, and NNN are agonists of $\alpha 7$-nAchR and the heteromeric $\alpha \beta \mathrm{nAChRs}$, respectively [87]; both these nitrosamines cause lung cancer in laboratory animals [88]. The affinity of NNK for $\alpha 7-n A C h R$ was found to be about 1,300-fold higher than for nicotine, whereas the affinity of NNN for the heteromeric $\alpha \beta \mathrm{nAChRs}$ was about 5,000-fold higher $[34,87]$. Because of their high affinity for nAChRs, NNK and NNN, rather than nicotine, might be the actual ligands for nAChRs in the context of smoking tobacco. Therefore, many of the addictive, neuropsychological, and cancer-stimulating effects from smoking that are currently attributed to nicotine are probably caused by these nitrosamines. In support of this hypothesis, a study displayed that the binding of NNK to $\alpha 7-n A C h R$ causes an influx of $\mathrm{Ca}^{2+}$ into lung cells, and the resulting membrane depolarization activated voltage-gated $\mathrm{Ca}^{2+}$ channels [49]. These eventually upregulated nAChRs expression [27, 89]. These data demonstrated a strong positive feedback loop associated with nAChR signaling that eventually causes normal cells to step into precancerous phase of transformation. Although all $\mathrm{nAChRs}$ are cation channels, they regulate diverse functions in a cell-type-specific manner. This functional diversity is also reflected in cancers of different cellular origins. In the following sections, the two latest and most important nAChR-induced cancer formation models will be illustrated.

\section{6. $\alpha 7$-nAChRs and Lung Cancer}

The presence of $\mathrm{nAChRs}$ in lung cancer cell lines has been well investigated since 1989-1990; the first report suggested that nicotine and NNK bound to nAChRs would stimulate the proliferation of human small cell lung cancer (SCLC) cells through autonomic nervous-system-dependent regulation of lung cancer cells $[81,90]$. This study was then reviewed by Maneckjee and Minna in 1990 and 1994 who demonstrated a nicotine-induced reversal of apoptosis in response to opioids in SCLC and NSCLC cell lines $[91,92]$. Another laboratory discovered that nicotine affects the proliferation of human SCLC cell lines by stimulating the release of serotonin, which acts as an autocrine growth factor in these cells [93]. In turn, these findings led to the hypothesis that human airway epithelial cells express all of the components required to synthesize and secrete members of the acetylcholine family and nAChR subtypes.

Nicotine exposure induces the augmented expression of $\alpha 7$-nAChRs, which causes an influx of $\mathrm{Ca}^{2+}$ and activates downstream signals, such as protein kinase C, Raf1, extracellular-signal regulated kinase (ERK) 1/2, and cMyc, leading to increases in cell proliferation, cancer cell migration, metastasis, or the inhibition of apoptosis. West and colleagues [66] suggested that redundant Akt activation by nicotine and its carcinogen derivative NNK could contribute to tobacco-related carcinogenesis in nonimmortalized human airway epithelial cells. In this study, normal human bronchial epithelial (NHBE) cell was forced to be transformed through nicotinic activation of Akt which alters epithelial cell growth characteristics. Dysregulated NHBE growth after nicotine administration is consistent with in vivo observations of active smokers in which increased proliferative indices were seen when compared with former smokers. Protection from prolonged serum-deprivationinduced apoptosis, conferred by nicotine was attenuated by LY294002 or by DH $\beta$ E, and protection conferred by NNK, was attenuated by LY294002 or by $\alpha$-BTX [66]. This study showed that, in addition to promoting cellular survival or transformation process, $\mathrm{nAChR}$ activation from nicotine or NNK-induced Akt signal is required for diminishing contact inhibition and cellular dependence on exogenous growth factors or extracellular matrix. It revealed that abundant $\alpha 7$ nAChR expression in human cancer cells could be selectively attenuated by specific antagonists. Recently, Schuller [94] also proved that NNK interacts with $\alpha 7 \mathrm{nAChRs,} \mathrm{resulting}$ in the development of lung cancer. The signals involved in normal cell transformation might be due to a significant reversible upregulation of the $\alpha 1, \alpha 5$, and $\alpha 7$ subunits in human bronchial epithelial cells, when these cells were exposed to nicotine $(100 \mathrm{nM})$ in vitro for 72 hours. Since studies have shown that $\alpha 7$ is the main nAChR subunit that mediates the proliferative effects of nicotine in lung cancer cells [33, 95-99], $\alpha 7-n$ AChR might be a valuable molecular target specifically for lung cancer therapy [100-102].

\section{7. $\alpha 9-n A C h R s$ and Breast Cancer}

The expression of estrogen receptors by breast cancer cells has provided a therapeutic target by using estrogen receptor antagonists, but their use contributes to an unfortunate stimulation of breast cancer development through the pharmacological use of estrogen, the ligand for the estrogen 
receptor. Estrogen was recently found to differentially modulate $\mathrm{nAChR}$ subtype [5], and the expression of nAChR by breast cancers may similarly provide a new target for breast cancer therapies, whereas nicotine, a ligand for $\mathrm{nAChR}$, was found to have stimulated breast cancer growth.

The $\alpha 9$-nAChR is a known homopentamer that plays a central role in coordinating keratinocyte adhesion and motility during wound healing [4]. Lee et al. [26] showed that $\alpha 9$-nAChRs were found to be ubiquitously expressed in many epithelial, lung, and breast cancer cell lines, and that most of the same cell lines also expressed $\alpha 5$ and $\alpha 10$-nAChRs [26]. The $\alpha 9$-nAChRs were present in primary tumors and nonmalignant breast tissue obtained from patients; however, breast cancer cells had increased $\alpha 9$-nAChR expression compared with the surrounding normal tissues. Lee et al. used MDA-MB-231 breast cancer cells, in which $\alpha 9$-nAChR expression had been silenced, to show that lowering $\alpha 9$-nAChR expression would reduce proliferation and tumorigenic potential in both in vitro and in vivo assays. Cells with inducible $\alpha 9$-nAChR gene expression were also generated from normal breast epithelial cells (MCF-10A) that were transformed by nicotine or NNK treatments, and experiments showed that increased $\alpha 9$-nAChR expression in vitro enhanced proliferation and colony formation. Likewise, mice that were subcutaneously injected with nicotine-transformed MCF-10A cells that inducibly expressed increased levels of $\alpha 9$-nAChRs showed enhanced tumor xenograft volumes when exposed to nicotine. Several studies have reported that nicotine decreases the cytotoxicity of doxorubicin, promotes migration via a signaling cascade involving protein kinase $\mathrm{C}$ and $\mathrm{cdc} 42$, and induces the proliferation, invasion, and epithelialmesenchymal transition of breast cancer cells [103-105]. These studies provided evidence that $\mathrm{nAChR}$, more specifically $\alpha 9$-nAChR, might play a major role in breast carcinogenesis, just as $\alpha 7-\mathrm{nAChR}$ is often associated with lung cancer [66], which further supports epidemiological studies that have revealed an association between breast cancer and exposure to cigarette smoke [106]. In conclusion, all the above demonstrated that $\alpha 9$-nAChRs expression knockdown can indeed inhibit breast cancer cell growth, whereas overexpression of $\alpha 9$-nAChRs, accompanied with long-term treatment nicotine, causes normal breast epithelial cell transformation both in vitro and in vivo experimental studies.

\section{Developing Drugs Targeted at nAChR}

8.1. nAChRs Agonist. Recent studies have shown that nicotine is not only a harmful product in cigarettes, but it is also a therapeutic nAChRs stimulator that enhances wound healing in preclinical models $[53,58,107,108]$. Notably, these studies were conducted in animal models, and no side effects of nAChR agonists or antagonists were reported. Several neurological diseases associated with aging have been linked to reduced angiogenesis in the brain, and changes in the levels of nAChR in vascular-related cells in Alzheimer's disease $[109,110]$, and this suggests that there could be a role for a nicotine-based therapy in neurological disorders.
Many of the studied, clinically used drugs that target nAChRs are administered for months, resulting in long-term changes in receptor properties and/or number. Accordingly, these drugs can be divided into two categories: $\alpha 7-\mathrm{nAChR}$ or non- $\alpha 7$-nAChR target agents. There are many potential drugs targeting nAChRs, and most of them are agonists and can be applied to treatment of various nervous-system disorders. For example, GTS-21, TC-5619, or EVP-6124 can be used for schizophrenia therapies [111]. The major target disease for a cognition enhancer is Alzheimer's disease. In Alzheimer's brain tissue, cortical nAChRs $(\alpha 4 \beta 2)$ are markedly reduced $(>80 \%)$, reflecting the cholinergic deficits associated with Alzheimer's disease [112]. Pilot trials using nicotine patches have demonstrated improved attention in Alzheimer's disease patients [113]. Interestingly, pharmacoepidemiological studies have shown a reduced incidence of Alzheimer's disease in populations of individuals who have previously smoked [114]. The potential protective effects of (-)-nicotine in this neurodegenerative disease may be related to neuroprotective properties observed with nicotine and other $\mathrm{nAChR}$ activators in in vitro and in vivo experimental studies. To our knowledge, Alzheimer's diseasespecific therapies are mainly agonists of $\alpha 7$-nAChR. For example, SSR-180711, MEM-3454/R-3487, MEM-63908/R4996, AZD-0328, and S-24795 are used. The $\alpha 4 \beta 2$-nAChR agonists are TC-1734 and S-38232; these drugs have shown promises in preclinical cognition models [111]. Other related drugs that act on the $\alpha 4 \beta 2-n A C h R$ can also be applied to smoking cessation, attention-deficit hyperactivity disorder, cognitive dysfunction, and depression [111].

8.2. nAChRs Antagonist. Neurotoxins are commonly used to distinguish between neuronal $\mathrm{nAChR}$ receptor subunit combinations $[115,116]$. The neurotoxins lophotoxin, neosurugatoxin, erysodine, $\alpha-\mathrm{BgT}$, and the alkaloids $\mathrm{DH} \beta \mathrm{E}$ are competitive nAChR antagonists that display selectivity for $\beta 2$-containing nAChRs, particularly the $\alpha 4 \beta 2$ subtype [117]. The latest study implied that nAChR antagonists can be used for anticancer drugs. While the $\alpha 7$-nAChRs are overexpressed in small-cell lung carcinoma in smokers [118], in vitro experiments have suggested that the malignant growth can be ceased using snake neurotoxins ( $\alpha$-neurotoxins) or snail conotoxins ( $\alpha$-conotoxins), and these have been used for the isolation and biochemical characterization of nAChRs because they are competitive antagonists of the nAChR [119]. The presence of $\alpha 7$-nAChR inhibitors, such as methyllycaconitine (MLA) and $\alpha$-bungarotoxin, was found to have reversed the proangiogenic effects of nicotine during cancer development process [50-52, 54]. Russo and colleagues demonstrated that several natural compounds significantly inhibited NSCLC cell proliferation or tumor growth by inhibition of $\alpha 7-\mathrm{nAChR}$ expression. These data determined a significant reduction of tumor growth in nude mice orthotopically engrafted with A549-luciferase cells ( $4.6 \%$ of living cells versus $31 \%$ in untreated mice). The specific $\alpha 7$-nAChR antagonists can undergo both induction of apoptosis protein (activates caspases 3, 9, 2, P53, and $\mathrm{Bad}$ ) and reduction of survival signaling (activates PI3KAkt, MAPK, and NF- $\kappa$ B pathways) in in vitro and in vivo 
experiments. These data suggested that $\alpha 7$-nAChR-targeted chemicals form a promising prospective in anticancer drug development. However, it must be noted that both $\alpha$ bungarotoxin and MLA also bind in high affinity to $\alpha 9$ nAChR. Therefore, there may be partial involvement of $\alpha 9$ $\mathrm{nAChR}$ in the proangiogenic effects of nicotine $[120,121]$.

Recently, the involvement of $\alpha 9-\mathrm{nAChR}$ in pain has been suggested by a number of experimental observations, and the administration of nAChR agonists reduces pain-related behaviors in several studies [122-124]. Virus-mediated overexpression of the $\alpha 9$-nAChR subtype was specifically found in breast cancer tumors [26]. Rather than using competitive nAChR inhibitors, nature compounds were investigated and shown to have inhibited cancer cell proliferation. For example, a very low concentration of garcinol $(1 \mu \mathrm{M})$ from the edible fruit Garcinia indica inhibited nicotine-induced breast cancer cell proliferation through the downregulation of $\alpha 9$-nAChR and cyclin D3 expression [27]. Other natural compounds, such as luteolin and quercetin, have also inhibited human breast cancer cell proliferation through the downregulation of cell surface $\alpha 9$-nAChR subunit expression in human breast cancer cells, and the combined treatment of cells with luteolin and quercetin synergistically inhibited AKT activation [28]. In another study, Tu et al. found that estradiol- and nicotine-induced $\alpha 9$-nAChR protein expression was blocked by epigallocatechin-3-gallate (EGCG) [125]. These findings suggested a possible chemopreventive ability of EGCG through the inhibition of estrogen- or nicotine-induced $\alpha 9-\mathrm{nAChR}$ protein expression, which is known to confer smoking-mediated breast tumorigenesis. All of these findings have provided molecular evidence for the possible chemopreventive or chemotherapeutic ability of smoking-mediated breast tumorigenesis. As always, a balance of regulating $\mathrm{nAChR}$ activity must be maintained between limiting pathological angiogenesis and causing potential toxicity to patients.

\section{Conclusion}

Epidemiological and experimental studies targeting nAChRs have clearly established that tobacco products cause cancers of various types. An improvement of understanding towards any relevant carcinogenic mechanisms will lead to new approaches for cancer prevention. Over the past two decades, several valuable tobacco carcinogen biomarkers have been discovered, which increases our insight into the mechanism of cancer induction. The multiple tumor-promoting effects caused by cigarette smoke and the carcinogens and toxicants in it must be targeted. The ideal drug to target these effects must have minimal toxicity in animal models and humans, which might be achievable through using naturally occurring compounds in doses no greater than those present in common foods, such as vegetables, to maintain homeostasis in the human body. At present, the majority of compounds under investigation are either agonists or partial agonists. Given the negative effects of nicotine on the immune system function, receptor subtype-selective antagonists might also be beneficial as therapeutic agents. The presence of nAChRs in tissues, in addition to the central and peripheral nervous systems, for example, immune system, gastrointestinal tract, lung, breast, and bladder, could offer additional therapeutic targets for receptor subtype-selective nAChR ligands when these become available.

\section{Acknowledgments}

This study was supported by the National Science Council (grant NSC 95-2320-B-038-016-MY3 to Dr. Y.-S. Ho and Grant NSC 96-2314-B-038-002 to Dr. Ch.-H. Wu) and by the CECR (DOH100-TD-C-111-008).

\section{References}

[1] H. M. Schuller, "Is cancer triggered by altered signalling of nicotinic acetylcholine receptors?" Nature Reviews Cancer, vol. 9, no. 3, pp. 195-205, 2009.

[2] S. S. Hecht and D. Hoffmann, "Tobacco-specific nitrosamines, an important group of carcinogens in tobacco and tobacco smoke," Carcinogenesis, vol. 9, no. 6, pp. 875-884, 1988.

[3] P. Song, H. S. Sekhon, X. W. Fu et al., "Activated cholinergic signaling provides a target in squamous cell lung carcinoma," Cancer Research, vol. 68, no. 12, pp. 4693-4700, 2008.

[4] P. Song, H. S. Sekhon, Y. Jia et al., "Acetylcholine is synthesized by and acts as an autocrine growth factor for small cell lung carcinoma," Cancer Research, vol. 63, no. 1, pp. 214-221, 2003.

[5] C. H. Lee, Y. C. Chang, C. S. Chen et al., "Crosstalk between nicotine and estrogen-induced estrogen receptor activation induces alpha9-nicotinic acetylcholine receptor expression in human breast cancer cells," Breast Cancer Research and Treatment. In press.

[6] H. A. N. Al-Wadei, M. H. Al-Wadei, T. Masi, and H. M. Schuller, "Chronic exposure to estrogen and the tobacco carcinogen NNK cooperatively modulates nicotinic receptors in small airway epithelial cells," Lung Cancer, vol. 69, no. 1, pp. 33-39, 2010.

[7] R. J. Hung, J. D. McKay, V. Gaborieau et al., "A susceptibility locus for lung cancer maps to nicotinic acetylcholine receptor subunit genes on 15q25," Nature, vol. 452, no. 7187, pp. 633637, 2008.

[8] P. Liu, H. G. Vikis, D. Wang et al., "Familial aggregation of common sequence variants on 15q24-25.1 in lung cancer," Journal of the National Cancer Institute, vol. 100, no. 18, pp. 1326-1330, 2008.

[9] J. Arredondo, A. I. Chernyavsky, D. L. Jolkovsky, K. E. Pinkerton, and S. A. Grando, "Receptor-mediated tobacco toxicity: acceleration of sequential expression of $\alpha 5$ and $\alpha 7$ nicotinic receptor subunits in oral keratinocytes exposed to cigarette smoke," FASEB Journal, vol. 22, no. 5, pp. 13561368, 2008.

[10] C. I. Amos, X. Wu, P. Broderick et al., "Genome-wide association scan of tag SNPs identifies a susceptibility locus for lung cancer at 15q25.1," Nature Genetics, vol. 40, no. 5, pp. 616-622, 2008.

[11] I. R. Schlaepfer, N. R. Hoft, A. C. Collins et al., "The CHRNA5/A3/B4 gene cluster variability as an important determinant of early alcohol and tobacco initiation in young adults," Biological Psychiatry, vol. 63, no. 11, pp. 1039-1046, 2008.

[12] H. M. Schuller, "Nitrosamines as nicotinic receptor ligands," Life Sciences, vol. 80, no. 24-25, pp. 2274-2280, 2007. 
[13] P. Russo, A. Catassi, A. Cesario, and D. Servent, "Development of novel therapeutic strategies for lung cancer: targeting the cholinergic system," Current Medicinal Chemistry, vol. 13, no. 29, pp. 3493-3512, 2006.

[14] J. Lindstrom, "Nicotinic acetylcholine receptors in health and disease," Molecular Neurobiology, vol. 15, no. 2, pp. 193-222, 1997.

[15] C. Gotti and F. Clementi, "Neuronal nicotinic receptors: from structure to pathology," Progress in Neurobiology, vol. 74, no. 6, pp. 363-396, 2004.

[16] C. M. Flores, R. M. DeCamp, S. Kilo, S. W. Rogers, and K. M. Hargreaves, "Neuronal nicotinic receptor expression in sensory neurons of the rat trigeminal ganglion: demonstration of $\alpha 3 \beta 4$, a novel subtype in the mammalian nervous system," Journal of Neuroscience, vol. 16, no. 24, pp. 7892-7901, 1996.

[17] S. E. McCallum, A. C. Collins, R. Paylor, and M. J. Marks, "Deletion of the beta 2 nicotinic acetylcholine receptor subunit alters development of tolerance to nicotine and eliminates receptor upregulation," Psychopharmacology, vol. 184, no. 3-4, pp. 314-327, 2006.

[18] R. Klink, A. De Kerchove D'Exaerde, M. Zoli, and J. P. Changeux, "Molecular and physiological diversity of nicotinic acetylcholine receptors in the midbrain dopaminergic nuclei," Journal of Neuroscience, vol. 21, no. 5, pp. 1452-1463, 2001.

[19] L. C. Gahring, E. L. Days, T. Kaasch et al., "Pro-inflammatory cytokines modify neuronal nicotinic acetylcholine receptor assembly," Journal of Neuroimmunology, vol. 166, no. 1-2, pp. 88-101, 2005.

[20] E. X. Albuquerque, E. F. R. Pereira, N. G. Castro et al., "Nicotinic receptor function in the mammalian central nervous system," Annals of the New York Academy of Sciences, vol. 757, pp. 48-72, 1995.

[21] R. S. Broide and F. M. Leslie, "The $\alpha 7$ nicotinic acetylcholine receptor in neuronal plasticity," Molecular Neurobiology, vol. 20, no. 1, pp. 1-16, 1999.

[22] M. Quik, J. Philie, and J. Choremis, "Modulation of $\alpha 7$ nicotinic receptor-mediated calcium influx by nicotinic agonists," Molecular Pharmacology, vol. 51, no. 3, pp. 499506, 1997.

[23] Y. S. Ho, C. H. Chen, Y. J. Wang et al., "Tobaccospecific carcinogen 4-(methylnitrosamino)-1-(3-pyridyl)-1butanone (NNK) induces cell proliferation in normal human bronchial epithelial cells through $\mathrm{NF} \kappa \mathrm{B}$ activation and cyclin D1 up-regulation," Toxicology and Applied Pharmacology, vol. 205, no. 2, pp. 133-148, 2005.

[24] R. J. Chen, Y. S. Ho, H. R. Guo, and Y. J. Wang, "Rapid activation of Stat 3 and ERK1/2 by nicotine modulates cell proliferation in human bladder cancer cells," Toxicological Sciences, vol. 104, no. 2, pp. 283-293, 2008.

[25] P. L. Wei, Y. J. Chang, Y. S. Ho et al., "Tobacco-specific carcinogen enhances colon cancer cell migration through alpha7-nicotinic acetylcholine receptor," Annals of Surgery, vol. 249, pp. 978-985, 2009.

[26] C. H. Lee, C. S. Huang, C. S. Chen et al., "Overexpression and activation of the alpha9-nicotinic receptor during tumorigenesis in human breast epithelial cells," Journal of the National Cancer Institute, vol. 102, pp. 1322-1335, 2010.

[27] C. S. Chen, C. H. Lee, C. D. Hsieh et al., "Nicotine-induced human breast cancer cell proliferation attenuated by garcinol through down-regulation of the nicotinic receptor and cyclin D3 proteins," Breast Cancer Research and Treatment, pp. 1$15,2010$.
[28] Y. L. Shih, H. C. Liu, C. S. Chen et al., "Combination treatment with luteolin and quercetin enhances antiproliferative effects in nicotine-treated MDA-MB-231 cells by down-regulating nicotinic acetylcholine receptors," Journal of Agricultural and Food Chemistry, vol. 58, no. 1, pp. 235-241, 2010.

[29] Y. Abreu-Villaça, F. J. Seidler, D. Qiao et al., "Short-term adolescent nicotine exposure has immediate and persistent effects on cholinergic systems: critical periods, patterns of exposure, dose thresholds," Neuropsychopharmacology, vol. 28, no. 11, pp. 1935-1949, 2003.

[30] R. G. Taylor, G. Woodman, and S. W. Clarke, "Plasma nicotine concentration and the white blood cell count in smokers," Thorax, vol. 41, no. 5, pp. 407-408, 1986.

[31] B. V. R. Sastry, M. B. Chance, G. Singh, J. L. Horn, and V. E. Janson, "Distribution and retention of nicotine and its metabolite, cotinine, in the rat as a function of time," Pharmacology, vol. 50, no. 2, pp. 128-136, 1995.

[32] C. T. C. Okoli, T. Kelly, and E. J. Hahn, "Secondhand smoke and nicotine exposure: a brief review," Addictive Behaviors, vol. 32, no. 10, pp. 1977-1988, 2007.

[33] J. Arredondo, A. I. Chernyavsky, and S. A. Grando, "The nicotinic receptor antagonists abolish pathobiologic effects of tobacco-derived nitrosamines on BEP2D cells," Journal of Cancer Research and Clinical Oncology, vol. 132, no. 10, pp. 653-663, 2006.

[34] J. Arredondo, A. I. Chernyavsky, and S. A. Grando, "Nicotinic receptors mediate tumorigenic action of tobacco-derived nitrosamines on immortalized oral epithelial cells," Cancer Biology and Therapy, vol. 5, no. 5, pp. 511-517, 2006.

[35] D. Kishino, K. Kiura, N. Takigawa et al., "Effect of gefitinib on N-nitrosamine-4-(methylnitrosamino)-1-(3-pyridyl)-1butanone induced lung tumorigenesis in A/J mice," Lung Cancer, vol. 65, no. 3, pp. 284-289, 2009.

[36] T. Nishioka, J. Guo, D. Yamamoto, L. Chen, P. Huppi, and C. Y. Chen, "Nicotine, through upregulating pro-survival signaling, cooperates with NNK to promote transformation," Journal of Cellular Biochemistry, vol. 109, no. 1, pp. 152-161, 2010.

[37] J. Mei, H. Hu, M. McEntee, H. Plummer, P. Song, and H. C. R. Wang, "Transformation of non-cancerous human breast epithelial cell line MCF10A by the tobacco-specific carcinogen NNK," Breast Cancer Research and Treatment, vol. 79, no. 1, pp. 95-105, 2003.

[38] H. M. Schuller, "Neurotransmitter receptor-mediated signaling pathways as modulators of carcinogenesis," Progress in Experimental Tumor Research, vol. 39, pp. 45-63, 2007.

[39] R. Girod, G. Crabtree, G. Ernstrom et al., "Heteromeric complexes of $\alpha 5$ and/or $\alpha 7$ subunits. Effects of calcium and potential role in nicotine-induced presynaptic facilitation," Annals of the New York Academy of Sciences, vol. 868, pp. 578590, 1999.

[40] S. Fucile, "Ca2+ permeability of nicotinic acetylcholine receptors," Cell Calcium, vol. 35, no. 1, pp. 1-8, 2004.

[41] V. Itier and D. Bertrand, "Neuronal nicotinic receptors: from protein structure to function," FEBS Letters, vol. 504, no. 3, pp. 118-125, 2001.

[42] J. M. Lindstrom, "Nicotinic acetylcholine receptors of muscles and nerves: comparison of their structures, functional roles, and vulnerability to pathology," Annals of the New York Academy of Sciences, vol. 998, pp. 41-52, 2003. 
[43] J. M. Cunningham, V. A. Lennon, E. H. Lambert, and B. Scheithauer, "Acetylcholine receptors in small cell carcinomas," Journal of Neurochemistry, vol. 45, no. 1, pp. 159-167, 1985.

[44] S. A. Grando, "Receptor-mediated action of nicotine in human skin," International Journal of Dermatology, vol. 40, no. 11, pp. 691-693, 2001.

[45] J. D. Minna, "Nicotine exposure and bronchial epithelial cell nicotinic acetylcholine receptor expression in the pathogenesis of lung cancer," Journal of Clinical Investigation, vol. 111, no. 1, pp. 31-33, 2003.

[46] R. Zeidler, K. Albermann, and S. Lang, "Nicotine and apoptosis," Apoptosis, vol. 12, no. 11, pp. 1927-1943, 2007.

[47] E. Sher, A. Codignola, M. Passafaro et al., "Nicotinic receptors and calcium channels in small cell lung carcinoma: functional role, modulation, and autoimmunity," Annals of the New York Academy of Sciences, vol. 841, pp. 606-624, 1998.

[48] B. M. Conti-Fine, D. Navaneetham, S. Lei, and A. D. J. Maus, "Neuronal nicotinic receptors in non-neuronal cells: new mediators of tobacco toxicity?" European Journal of Pharmacology, vol. 393, no. 1-3, pp. 279-294, 2000.

[49] B. J. Sheppard, M. Williams, H. K. Plummer, and H. M. Schuller, "Activation of voltage-operated $\mathrm{Ca}^{+}$-channels in human small cell lung carcinoma by the tobaccospecific nitrosamine 4-(methylnitrosamino)-1-(3-pyridyl)1-butanone," International Journal of Oncology, vol. 16, no. 3, pp. 513-518, 2000.

[50] C. Heeschen, J. J. Jang, M. Weis et al., "Nicotine stimulates angiogenesis and promotes tumor growth and atherosclerosis," Nature Medicine, vol. 7, no. 7, pp. 833-839, 2001.

[51] C. Heeschen, M. Weis, and J. P. Cooke, "Nicotine promotes arteriogenesis," Journal of the American College of Cardiology, vol. 41, no. 3, pp. 489-496, 2003.

[52] C. Heeschen, M. Weis, A. Aicher, S. Dimmeler, and J. P. Cooke, "A novel angiogenic pathway mediated by nonneuronal nicotinic acetylcholine receptors," Journal of Clinical Investigation, vol. 110, no. 4, pp. 527-536, 2002.

[53] J. P. Cooke and H. Bitterman, "Nicotine and angiogenesis: a new paradigm for tobacco-related diseases," Annals of Medicine, vol. 36, no. 1, pp. 33-40, 2004.

[54] P. Dasgupta and S. P. Chellappan, "Nicotine-mediated cell proliferation and angiogenesis: new twists to an old story," Cell Cycle, vol. 5, no. 20, pp. 2324-2328, 2006.

[55] P. Dasgupta, R. Kinkade, B. Joshi, C. DeCook, E. Haura, and S. Chellappan, "Nicotine inhibits apoptosis induced by chemotherapeutic drugs by up-regulating XIAP and survivin," Proceedings of the National Academy of Sciences of the United States of America, vol. 103, no. 16, pp. 6332-6337, 2006.

[56] R. D. Egleton, K. C. Brown, and P. Dasgupta, "Angiogenic activity of nicotinic acetylcholine receptors: implications in tobacco-related vascular diseases," Pharmacology and Therapeutics, vol. 121, no. 2, pp. 205-223, 2009.

[57] A. Avogaro and G. P. Fadini, "The janus face of nicotinic angiogenesis," Journal of the American College of Cardiology, vol. 48, no. 12, pp. 2561-2563, 2006.

[58] J. P. Cooke, "Angiogenesis and the role of the endothelial nicotinic acetylcholine receptor," Life Sciences, vol. 80, no. 2425, pp. 2347-2351, 2007.

[59] D. Adamopoulos, P. Van De Borne, and J. F. Argacha, "New insights into the sympathetic, endothelial and coronary effects of nicotine," Clinical and Experimental Pharmacology and Physiology, vol. 35, no. 4, pp. 458-463, 2008.
[60] M. Chu, J. Guo, and C. Y. Chen, "Long-term exposure to nicotine, via Ras pathway, induces cyclin D1 to stimulate G cell cycle transition," Journal of Biological Chemistry, vol. 280, no. 8, pp. 6369-6379, 2005.

[61] B. S. Conklin, W. Zhao, D. S. Zhong, and C. Chen, "Nicotine and cotinine up-regulate vascular endothelial growth factor expression in endothelial cells," American Journal of Pathology, vol. 160, no. 2, pp. 413-418, 2002.

[62] L. Xu and X. Deng, "Protein kinase Ciota promotes nicotineinduced migration and invasion of cancer cells via phosphorylation of micro- and m-calpains," The Journal of Biological Chemistry, vol. 281, pp. 4457-4466, 2006.

[63] V. Y. Shin, W. K. K. Wu, K. M. Chu et al., "Nicotine induces cyclooxygenase-2 and vascular endothelial growth factor receptor-2 in association with tumor-associated invasion and angiogenesis in gastric cancer," Molecular Cancer Research, vol. 3, no. 11, pp. 607-615, 2005.

[64] M. K. C. Ng, J. Wu, E. Chang et al., "A central role for nicotinic cholinergic regulation of growth factor-induced endothelial cell migration," Arteriosclerosis, Thrombosis, and Vascular Biology, vol. 27, no. 1, pp. 106-112, 2007.

[65] J. Yu, N. F. Huang, K. D. Wilson et al., "NAChRs mediate human embryonic stem cell-derived endothelial cells: proliferation, apoptosis, and angiogenesis," PLOS ONE, vol. 4, no. 9, article e7040, 2009.

[66] K. A. West, J. Brognard, A. S. Clark et al., "Rapid Akt activation by nicotine and a tobacco carcinogen modulates the phenotype of normal human airway epithelial cells," Journal of Clinical Investigation, vol. 111, no. 1, pp. 81-90, 2003.

[67] J. Tsurutani, S. S. Castillo, J. Brognard et al., "Tobacco components stimulate Akt-dependent proliferation and $\mathrm{NF} \kappa \mathrm{B}-$ dependent survival in lung cancer cells," Carcinogenesis, vol. 26, no. 7, pp. 1182-1195, 2005.

[68] E. Gemenetzidis, A. Bose, A. M. Riaz et al., "FOXM1 upregulation is an early event in human squamous cell carcinoma and it is enhanced by nicotine during malignant transformation," PLoS ONE, vol. 4, no. 3, article e4849, 2009.

[69] S. S. Hecht, "Cigarette smoking and lung cancer: chemical mechanisms and approaches to prevention," Lancet Oncology, vol. 3, no. 8, pp. 461-469, 2002.

[70] R. B. Everson, E. Randerath, R. M. Santella, T. A. Avitts, I. B. Weinstein, and K. Randerath, "Quantitative associations between DNA damage in human placenta and maternal smoking and birth weight," Journal of the National Cancer Institute, vol. 80, no. 8, pp. 567-576, 1988.

[71] R. K. Lin, Y. S. Hsieh, P. Lin et al., "The tobacco-specific carcinogen NNK induces DNA methyltransferase 1 accumulation and tumor suppressor gene hypermethylation in mice and lung cancer patients," Journal of Clinical Investigation, vol. 120, no. 2, pp. 521-532, 2010.

[72] E. R. Spindel, "Is nicotine the estrogen of lung cancer?" American Journal of Respiratory and Critical Care Medicine, vol. 179, no. 12, pp. 1081-1082, 2009.

[73] J. Zuo, J. Treadaway, T. W. Buckner, and B. Fritzsch, "Visualization of $\alpha 9$ acetylcholine receptor expression in hair cells of transgenic mice containing a modified bacterial artificial chromosome," Proceedings of the National Academy of Sciences of the United States of America, vol. 96, no. 24, pp. 14100-14105, 1999.

[74] I. Wessler, C. J. Kirkpatrick, and K. Racké, "Non-neuronal acetylcholine, a locally acting molecule, widely distributed in biological systems: expression and function in humans," 
Pharmacology and Therapeutics, vol. 77, no. 1, pp. 59-79, 1998.

[75] H. S. Sekhon, J. Yibing, R. Raab et al., "Prenatal nicotine increases pulmonary $\alpha 7$ nicotinic receptor expression and alters fetal lung development in monkeys," Journal of Clinical Investigation, vol. 103, no. 5, pp. 637-647, 1999.

[76] I. Wessler and C. J. Kirkpatrick, "Acetylcholine beyond neurons: the non-neuronal cholinergic system in humans," British Journal of Pharmacology, vol. 154, no. 8, pp. 15581571, 2008.

[77] Y. Z. Fan, H. Chang, YE. Yu, J. Liu, and R. Wang, “Thymosin $\alpha$ suppresses proliferation and induces apoptosis in human leukemia cell lines," Peptides, vol. 27, no. 9, pp. 2165-2173, 2006.

[78] J. Gould, H. L. Reeve, P. F. T. Vaughan, and C. Peers, "Nicotinic acetylcholine receptors in human neuroblastoma (SH-SY5Y) cells," Neuroscience Letters, vol. 145, no. 2, pp. 201-204, 1992.

[79] R. M. Yan, Y. M. Chiung, C. Y. Pan, J. H. Liu, and P. S. Liu, "Effects of dichlorobenzene on acetylcholine receptors in human neuroblastoma SH-SY5Y cells,” Toxicology, vol. 253, no. 1-3, pp. 28-35, 2008.

[80] S. Zhang, S. Togo, K. Minakata et al., "Distinct roles of cholinergic receptors in small cell lung cancer cells," Anticancer Research, vol. 30, no. 1, pp. 97-106, 2010.

[81] H. M. Schuller, "Cell type specific, receptor-mediated modulation of growth kinetics in human lung cancer cell lines by nicotine and tobacco-related nitrosamines," Biochemical Pharmacology, vol. 38, no. 20, pp. 3439-3442, 1989.

[82] D. C. L. Lam, L. Girard, R. Ramirez et al., "Expression of nicotinic acetylcholine receptor subunit genes in non-smallcell lung cancer reveals differences between smokers and nonsmokers," Cancer Research, vol. 67, no. 10, pp. 46384647, 2007.

[83] X. Sun, J. D. Ritzenthaler, X. Zhong, Y. Zheng, J. Roman, and S. Han, "Nicotine stimulates PPAR $\beta / \delta$ expression in human lung carcinoma cells through activation of P13K/mTOR and suppression of AP-2 $\alpha$," Cancer Research, vol. 69, no. 16, pp. 6445-6453, 2009.

[84] S. A. Grando, "Basic and clinical aspects of non-neuronal acetylcholine: biological and clinical significance of noncanonical ligands of epithelial nicotinic acetylcholine receptors," Journal of Pharmacological Sciences, vol. 106, no. 2, pp. 174-179, 2008.

[85] L. Paleari, A. Cesario, M. Fini, and P. Russo, “ $\alpha 7$-Nicotinic receptor antagonists at the beginning of a clinical era for NSCLC and Mesothelioma?" Drug Discovery Today, vol. 14, no. 17-18, pp. 822-836, 2009.

[86] A. Paliwal, T. Vaissière, A. Krais et al., "Aberrant DNA methylation links cancer susceptibility locus $15 \mathrm{q} 25.1$ to apoptotic regulation and lung cancer," Cancer Research, vol. 70, no. 7, pp. 2779-2788, 2010.

[87] H. M. Schuller and M. Orloff, "Tobacco-specific carcinogenic nitrosamines: ligands for nicotinic acetylcholine receptors in human lung cancer cells," Biochemical Pharmacology, vol. 55, no. 9, pp. 1377-1384, 1998.

[88] S. S. Hecht, "Tobacco smoke carcinogens and lung cancer," Journal of the National Cancer Institute, vol. 91, no. 14, pp. 1194-1210, 1999.

[89] H. K. Plummer, M. Dhar, and H. M. Schuller, "Expression of the $\alpha 7$ nicotinic acetylcholine receptor in human lung cells," Respiratory Research, vol. 6, p. 29, 2005.
[90] S. F. Saccone, A. L. Hinrichs, N. L. Saccone et al., "Cholinergic nicotinic receptor genes implicated in a nicotine dependence association study targeting 348 candidate genes with 3713 SNPs," Human Molecular Genetics, vol. 16, no. 1, pp. 36-49, 2007.

[91] R. Maneckjee and J. D. Minna, "Opioid and nicotine receptors affect growth regulation of human lung cancer cell lines," Proceedings of the National Academy of Sciences of the United States of America, vol. 87, no. 9, pp. 3294-3298, 1990.

[92] R. Maneckjee and J. D. Minna, "Opioids induce while nicotine suppresses apoptosis in human lung cancer cells," Cell Growth and Differentiation, vol. 5, no. 10, pp. 1033-1040, 1994.

[93] M. G. Cattaneo, A. Codignola, L. M. Vicentini, F. Clementi, and E. Sher, "Nicotine stimulates a serotonergic autocrine loop in human small-cell lung carcinoma," Cancer Research, vol. 53, no. 22, pp. 5566-5568, 1993.

[94] H. M. Schuller, "Neurotransmission and cancer: implications for prevention and therapy," Anti-Cancer Drugs, vol. 19, no. 7, pp. 655-671, 2008.

[95] L. Paleari, A. Catassi, M. Ciarlo et al., "Role of $\alpha 7$-nicotinic acetylcholine receptor in human non-small cell lung cancer proliferation," Cell Proliferation, vol. 41, no. 6, pp. 936-959, 2008.

[96] Y. Zheng, J. D. Ritzenthaler, J. Roman, and S. Han, "Nicotine stimulates human lung cancer cell growth by inducing fibronectin expression," American Journal of Respiratory Cell and Molecular Biology, vol. 37, no. 6, pp. 681-690, 2007.

[97] P. Dasgupta, S. Rastogi, S. Pillai et al., "Nicotine induces cell proliferation by $\beta$-arrestin-mediated activation of Src and Rb-Raf-1 pathways," Journal of Clinical Investigation, vol. 116, no. 8, pp. 2208-2217, 2006.

[98] S. Trombino, A. Cesario, S. Margaritora et al., " $\alpha 7$-nicotinic acetylcholine receptors affect growth regulation of human mesothelioma cells: role of mitogen-activated protein kinase pathway," Cancer Research, vol. 64, no. 1, pp. 135-145, 2004.

[99] L. Paleari, A. Grozio, A. Cesario, and P. Russo, "The cholinergic system and cancer," Seminars in Cancer Biology, vol. 18, no. 3, pp. 211-217, 2008.

[100] L. Paleari, F. Sessa, A. Catassi et al., "Inhibition of nonneuronal alpha7-nicotinic receptor reduces tumorigenicity in A549 NSCLC xenografts," International Journal of Cancer, vol. 125, pp. 199-211, 2009.

[101] L. Paleari, E. Negri, A. Catassi et al., "Inhibition of nonneuronal alpha7-nicotinic receptor for lung cancer treatment," American Journal of Respiratory and Critical Care Medicine, vol. 179, pp. 1141-1150, 2009.

[102] R. M. Eglen, "Muscarinic receptor subtype pharmacology and physiology," Progress in Medicinal Chemistry, vol. 43, pp. 105-136, 2005.

[103] P. Dasgupta, W. Rizwani, S. Pillai et al., "Nicotine induces cell proliferation, invasion and epithelial-mesenchymal transition in a variety of human cancer cell lines," International Journal of Cancer, vol. 124, no. 1, pp. 36-45, 2009.

[104] Y. Zhou, X. Gu, E. Ashayeri, R. Zhang, and R. Sridhar, "Nicotine decreases the cytotoxicity of doxorubicin towards MCF-7 and KB-3.1 human cancer cells in culture," Journal of the National Medical Association, vol. 99, no. 4, pp. 319-327, 2007.

[105] J. Guo, S. Ibaragi, T. Zhu et al., "Nicotine promotes mammary tumor migration via a signaling cascade involving protein kinase C and cdc42," Cancer Research, vol. 68, no. 20, pp. 8473-8481, 2008. 
[106] K. C. Johnson and S. A. Glantz, "Evidence secondhand smoke causes breast cancer in 2005 stronger than for lung cancer in 1986," Preventive Medicine, vol. 46, no. 6, pp. 492-496, 2008.

[107] J. Jacobi, J. J. Jang, U. Sundram, H. Dayoub, L. F. Fajardo, and J. P. Cooke, "Nicotine accelerates angiogenesis and wound healing in genetically diabetic mice," American Journal of Pathology, vol. 161, no. 1, pp. 97-104, 2002.

[108] N. Morimoto, S. Takemoto, T. Kawazoe, and S. Suzuki, "Nicotine at a low concentration promotes wound healing," Journal of Surgical Research, vol. 145, no. 2, pp. 199-204, 2008.

[109] T. Teaktong, A. J. Graham, J. A. Court et al., "Nicotinic acetylcholine receptor immunohistochemistry in Alzheimer's disease and dementia with Lewy bodies: differential neuronal and astroglial pathology," Journal of the Neurological Sciences, vol. 225, no. 1-2, pp. 39-49, 2004.

[110] W. F. Yu, Z. Z. Guan, N. Bogdanovic, and A. Nordberg, "High selective expression of alpha7 nicotinic receptors on astrocytes in the brains of patients with sporadic Alzheimer's disease and patients carrying Swedish APP 670/671 mutation: a possible association with neuritic plaques," Experimental Neurology, vol. 192, pp. 215-225, 2005.

[111] A. Taly, P. J. Corringer, D. Guedin, P. Lestage, and J. P. Changeux, "Nicotinic receptors: allosteric transitions and therapeutic targets in the nervous system," Nature Reviews Drug Discovery, vol. 8, no. 9, pp. 733-750, 2009.

[112] C. M. Martin-Ruiz, J. A. Court, E. Molnar et al., "Alpha4 but not alpha3 and alpha7 nicotinic acetylcholine receptor subunits are lost from the temporal cortex in Alzheimer's disease," Journal of Neurochemistry, vol. 73, pp. 1635-1640, 1999.

[113] E. D. Levin and B. B. Simon, "Nicotinic acetylcholine involvement in cognitive function in animals," Psychopharmacology (Berl), vol. 138, pp. 217-230, 1998.

[114] P. N. Lee, "Smoking and Alzheimer's disease: a review of the epidemiological evidence," Neuroepidemiology, vol. 13, no. 4, pp. 131-144, 1994.

[115] C. W. Luetje, K. Wada, S. Rogers et al., "Neurotoxins distinguish between different neuronal nicotinic acetylcholine receptor subunit combinations," Journal of Neurochemistry, vol. 55, no. 2, pp. 632-640, 1990.

[116] M. W. Decker, D. J. Anderson, J. D. Brioni et al., "Erysodine, a competitive antagonist at neuronal nicotinic acetylcholine receptors," European Journal of Pharmacology, vol. 280, no. 1, pp. 79-89, 1995.

[117] M. W. Holladay, M. J. Dart, and J. K. Lynch, "Neuronal nicotinic acetylcholine receptors as targets for drug discovery," Journal of Medicinal Chemistry, vol. 40, no. 26, pp. 41694194, 1997.

[118] M. A. Sciamanna, G. E. Griesmann, C. L. Williams, and V. A. Lennon, "Nicotinic acetylcholine receptors of muscle and neuronal $(\alpha)$ types coexpressed in a small cell lung carcinoma," Journal of Neurochemistry, vol. 69, no. 6, pp. 2302-2311, 1997.

[119] D. W. Sandall, N. Satkunanathan, D. A. Keays et al., "A novel $\alpha$-conotoxin identified by gene sequencing is active in suppressing the vascular response to selective stimulation of sensory nerves in vivo," Biochemistry, vol. 42, no. 22, pp. 6904-6911, 2003.

[120] J. M. McIntosh, A. D. Santos, and B. M. Olivera, "Conus peptides targeted to specific nicotinic acetylcholine receptor subtypes," Annual Review of Biochemistry, vol. 68, pp. 59-88, 1999.
[121] H. R. Arias and M. P. Blanton, “ $\alpha$-Conotoxins," International Journal of Biochemistry and Cell Biology, vol. 32, no. 10, pp. 1017-1028, 2000.

[122] M. I. Damaj, W. Glassco, M. D. Aceto, and B. R. Martin, "Antinociceptive and pharmacological effects of metanicotine, a selective nicotinic agonist," Journal of Pharmacology and Experimental Therapeutics, vol. 291, no. 1, pp. 390-398, 1999.

[123] S. D. Gilbert, T. M. Clark, and C. M. Flores, "Antihyperalgesic activity of epibatidine in the formalin model of facial pain," Pain, vol. 89, no. 2-3, pp. 159-165, 2001.

[124] Y. Wang, D. M. Su, R. H. Wang, Y. Liu, and H. Wang, "Antinociceptive effects of choline against acute and inflammatory pain," Neuroscience, vol. 132, no. 1, pp. 49-56, 2005.

[125] S. H. Tu, C. Y. Ku, C. T. Ho et al., "Tea polyphenol ()-epigallocatechin-3-gallate inhibits nicotine- and estrogeninduced alpha9-nicotinic acetylcholine receptor upregulation in human breast cancer cells," Molecular Nutrition \& Food Research, vol. 55, pp. 455-466, 2011. 


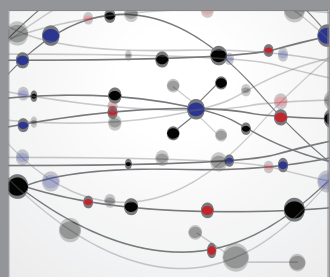

The Scientific World Journal
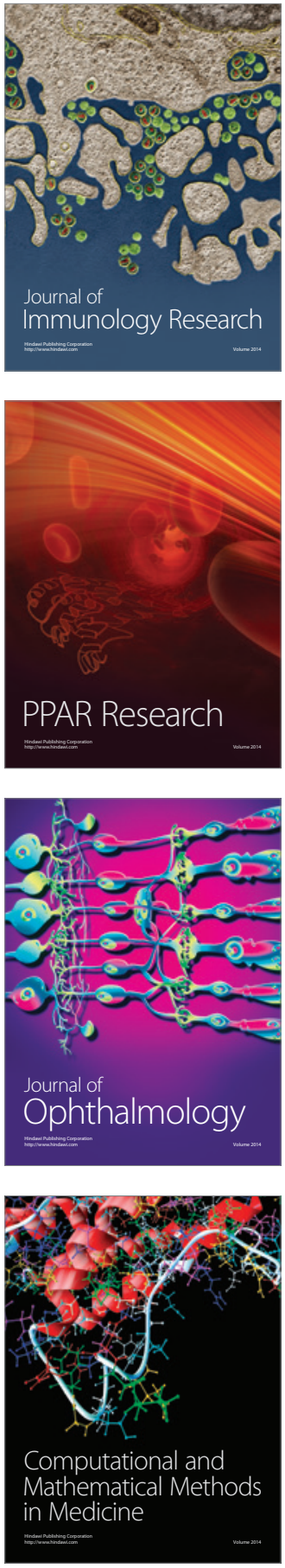

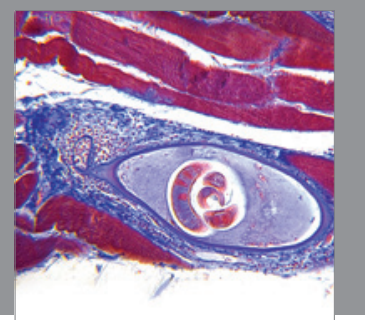

Gastroenterology

Research and Practice
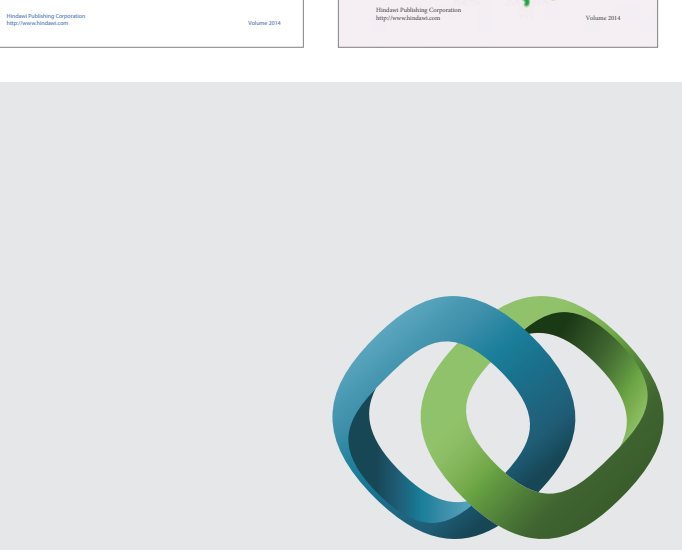

\section{Hindawi}

Submit your manuscripts at

http://www.hindawi.com
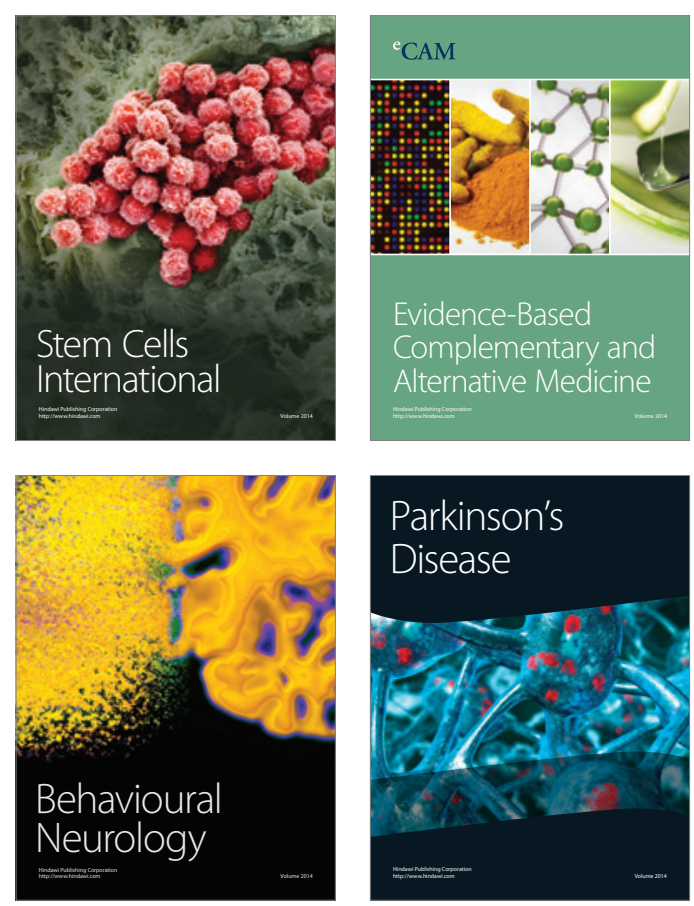

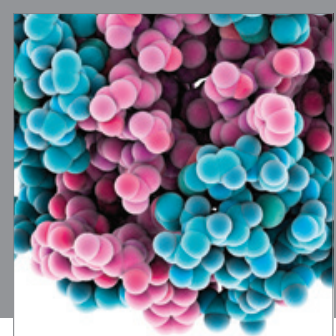

Journal of
Diabetes Research

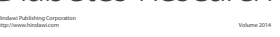

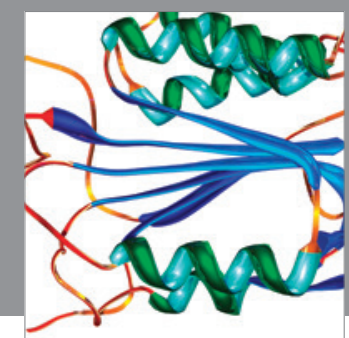

Disease Markers
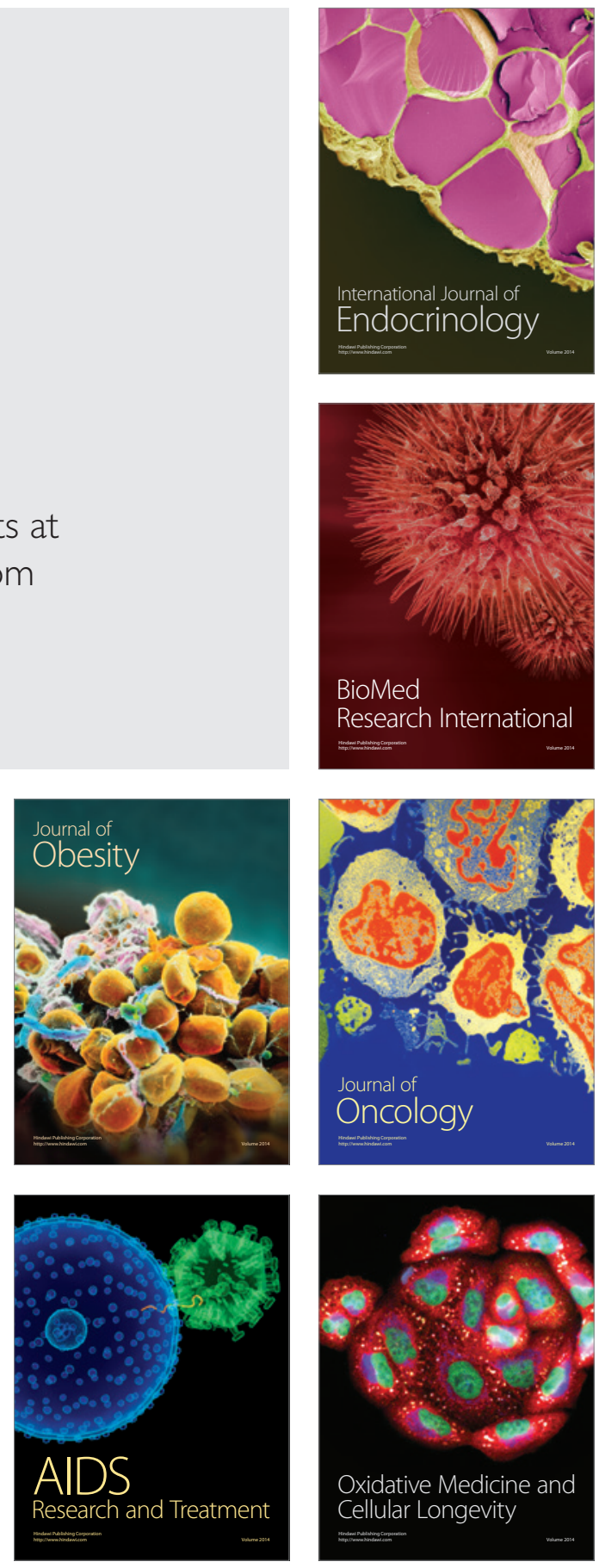